\title{
As redes de práticas educativas inovadoras no Brasil
}

Gabriela Freitas de Almeida Universidade de Brasília, Brasil

\section{Resumo}

Esse texto tem a intenção de analisar as redes de discussão e disseminação de práticas educativas alternativas que vem se desenvolvendo no Brasil. Num primeiro momento, trazemos um histórico das práticas educativas alternativas no Brasil. Posteriormente elencamos algumas redes sociais e grupos que têm se construído para apoiar e disseminar essas práticas, além de permitir a discussão e resolução dos problemas diários que se colocam nas escolas. E por último, a partir do trabalho de Paula Sibilia (2012), colocamos a importância dessas redes e desses espaços para a reflexão e desenvolvimento das práticas educativas alternativas.

Palavras-chave: Educação alternativa. Escolas inovadoras. Redes de práticas educativas.

\section{Abstract}

This paper intends to analyze the discussion and dissemination networks of alternative educational practices that are in development in Brazil. First, we present a history of alternative educational practices in Brazil. Subsequently, we list some networks and groups that have been structured to support and disseminate these practices, as well as allow discussion and resolution of the daily situations that arise in schools. And at last, based on the work of Paula Sibilia (2012), we place the importance of these networks and spaces for the reflection and development of alternative educational practices.

Keywords: Alternative education. Innovative schools. Educational practices networks. 


\section{Resumen}

Este texto tiene la intención de analizar las redes de discusión y diseminación de prácticas educativas alternativas que vienen desarrollándose en Brasil. En un primer momento, traemos un historial de las prácticas educativas alternativas en Brasil. Posteriormente, enumeramos algunas redes sociales y grupos que se han construido para apoyar y diseminar esas prácticas, además de permitir la discusión y resolución de los problemas diarios que se plantean en las escuelas. Y por último, a partir del trabajo de Paula Sibilia (2012), ponemos la importancia de esas redes y de esos espacios para la reflexión y el desarrollo de las prácticas educativas alternativas.

Palabras clave: Educación alternativa, escuelas innovadoras, redes de prácticas educativas.

\section{Resumé}

Cet article veut analyser les réseaux de discussion et de diffusion des pratiques éducatives alternatives qui se développent au Brésil. D'abord, on aborde l'histoire de ces pratiques. Par la suite, on a énuméré quelques réseaux sociaux et groupes qui ont été construits pour soutenir et diffuser ces pratiques, ainsi que pour permettre la discussion et la résolution des problèmes quotidiens qui se posent aux écoles. Enfin, tout en regardant le travail de Paula Sibilia (2012), on met en situation l'importance de ces réseaux et des espaces de réflexion et de développement de pratiques éducatives alternatives.

Mots-clés: Éducation alternative. Écoles innovantes. Réseaux de pratiques éducatives. 


\section{INTRODUÇÃO}

\section{O Desenvolvimento das Práticas Educativas Alternativas no Brasil}

Práticas educacionais alternativas existem desde que existem as práticas educacionais hegemônicas. Desde que se instituiu o que era normal, naturalmente, surge o que foge dessa normalidade, o que se constrói a partir dela e em contraposição a ela.

A existência de padrões não nasce na educação, mas é um reflexo da sociedade. Bem antes de existirem escolas ou espaços específicos de aprendizagem, regras sociais já existiam, padrões de como agir ou ser, já havia a tradição, já existiam valores comuns que permitiam a convivência humana, já existia uma moral que orientava costumes. O repasse desses padrões se confunde com a própria educação. É na aprendizagem das formas de conviver com a sociedade e com o mundo, no repasse das tradições, que as gerações mais novas se tornam parte dessa mesma sociedade e, ao mesmo tempo, enquanto subjetividades devem ter a possibilidade de recriá-la, "(...) Nesse sentido, a tradição é um fator fundamental para que possa existir um 'nós' e não apenas um 'eu' ou um conjunto de 'eus'" (Almeida, 2015). Nessa perspectiva, a tradição se coloca enquanto uma necessidade social, no entanto, não deve ser vista como isenta de significados e escolhas, como Almeida (2015) acrescenta:

Se o passado é simplesmente um conjunto de fatos, a tradição, nas palavras de Hannah Arendt (2003, p. 31), "seleciona e nomeia, transmite e preserva, indica onde se encontram os tesouros e qual o seu valor". Ela pressupõe, portanto, opções baseadas em determinados valores e princípios. Podemos dizer que ela faz uma "leitura" do passado e, desse modo, não representa um relato "objetivo" ou neutro, mas diz respeito a uma herança que depende de escolhas tanto daqueles que a entregam como daqueles que a recebem.

Respeitada a importância da tradição na construção de coletividades (e, ao 
mesmo tempo, especificando que ao falar de tradição não se tem em mente a tendência pedagógica tradicional ou a escola tradicional), também colocamos a importância da reconstrução das tradições, da reconstrução social e da construção de novos valores e princípios que norteiem nossa sociedade. Reiteramos que esse processo de transformação e construção de novas tradições também não são objetivas e neutras, mas fruto da constante tensão social e disputa de narrativas dos diversos grupos sociais.

Por mais que critérios do que seja socialmente desejável sempre tenham existido, foi com a modernidade que essa padronização ampliou seus horizontes na educação. A busca por esses padrões teve grande impulso com a criação da escola moderna, e a ampliação da educação formal a todas as pessoas e não apenas dos mais ricos, sob a hipótese de que a aquisição de conhecimentos específicos comuns possibilitaria uma melhor atuação na sociedade. Ou seja, supunha que a escola deveria ser o espaço onde todos poderiam desenvolver habilidades básicas para compreender e participar das estruturas sociais: ser um cidadão e ser útil e produtivo à sociedade.

Saindo da esfera da utopia, a padronização dos conhecimentos mínimos necessários ao bom cidadão/profissional é a opção política por um determinado tipo de cidadão que se deseja formar. Ao mesmo tempo essa padronização deslegitima milhares de outros conhecimentos que acabam fora das grades curriculares escolares e, dessa forma, deslegitima os detentores desses conhecimentos e cria hierarquização entre as pessoas. Para Illich (2007), esse formato educacional e de sociedade cria novas classes de pobreza, onde se encontram todos os que não se adequam aos padrões por ela criados. Para o autor:

departamentos de bem-estar social reivindicam um monopólio profissional, político e financeiro sobre a imaginação social, estabelecendo padrões para o que é proveitoso e o que é possível. Este monopólio está na raiz da modernização da pobreza. Qualquer 
simples necessidade, para a qual foi encontrada resposta institucional permite a invenção de nova classe de pobres e nova definição de pobreza (Illich, 2007, p. 09).

A disseminação de uma única forma de educar também traz consigo a ideia de que o indivíduo é responsável pela sua ascensão social, por se manter no caminho destinado a ele e alcançar os objetivos pretendidos. Em se tratando de uma pretensa igualdade escolar, o indivíduo é responsável e penalizado socialmente por não atingir os mesmos resultados que os outros, por não se manter no padrão designado pela tradição. Dessa forma, com a modernidade, ganha-se força uma educação que se pretende normatizadora e acessível para todos os grupos sociais, e nivela todas as pessoas a partir de um formato único de ação pedagógica e baseada na disciplina escolar.

Da mesma forma como sempre existiram as práticas pedagógicas consideradas como padrão de qualidade, a cada época também existiram aquelas que a contrapunham, por motivos diversos. Vários termos foram designados para se referir a essas práticas pedagógicas: alternativas, contrahegemônicas, inovadoras, desescolarizada, emancipadora, criativas, não formal, nova etc. Seria ingênuo pensar que esses termos não carregam consigo uma história e conceitos que os diferenciam, ou que não carregam uma carga própria de significado e sentidos, formado a partir de sua utilização na história, do ponto de vista daqueles que o disseminaram, e de suas concepções de sociedade.

Entre influências do contexto brasileiro, e do contexto internacional na luta contra o capitalismo, ou na constante modificação em busca de novas possibilidades de existência, as escolas e outras propostas educacionais também foram sendo construídas e transformadas no Brasil, a partir da realidade de cada local. Cambi (1999) descreve o início dos movimentos 
educacionais contra-hegemônicos no Brasil a partir do fim do século XIX ao afirmar que na década de 1890 (ou pouco antes) aparecem, apenas em nível teórico, os primeiros modelos de ruptura e as primeiras vozes de dissensão e renovação. No entanto, surgem como vozes de intelectuais isolados, particularmente. Como exemplo, Saviani (2008), traz os anarquistas, e a forma sobre como se organizavam e atuavam.

Os anarquistas no Brasil estudavam os autores libertários extraindo deles os principais conceitos educacionais como o de 'educação integral', oriundo da concepção de Robin, e 'ensino racionalista', proveniente de Ferrer os traduzia e divulgava na imprensa operária. Mas não ficavam apenas no estudo, buscavam torna-los realidade por meio da criação de universidades populares, centros de estudos sociais e escolas, com destaque para as Escolas Modernas inspiradas em Francisco Ferrer - autor do método racionalista, mas executado em 1909 pelo governo espanhol pelo crime de professar ideias libertárias. Após sua morte essas escolas proliferaram no Brasil, mas foram alvo de perseguição policial. A última delas teve suas portas fechadas em 1919 (Saviani, 2008, p. 13).

Um segundo grande ciclo da influência das práticas pedagógicas na educação brasileira foi o apoio dado pelos socialistas às práticas da escola nova. Por mais que essas não representassem seu ideal de prática pedagógica, consideravam que ela apresentava rupturas com a educação positivista da época, e em conformidade com a ideia de execução de uma revolução democrático-burguesa defendida como etapa anterior à revolução socialista. Como explica Saviani (2008) no Brasil, as Escolas Novas funcionaram e ganharam apoio do "(...) Partido Comunista Brasileiro na forma da participação na revolução democrático-burguesa como condição prévia para se colocar, no momento seguinte, a questão da revolução socialista ".

As Escolas Novas se reinventavam dentro do sistema capitalista, a partir das necessidades deste, proporcionando uma nova visão pedagógica do processo educativo, instituindo como elementos principais do trabalho pedagógico a construção do conhecimento a partir da atividade prática e 
o trabalho coletivo.

Kruspkaia (2017), educadora responsável pela educação russa durante a primeira fase da Revolução de Russa de 1917, já analisa a natureza das escolas novas atentando para o fato delas separarem as crianças dos problemas diários e reais de sua comunidade, impedirem o aparecimento das contradições sociais pelo convívio entre os diferentes, já que nas Escolas Novas ou Ginásios Rurais, existe um alto valor a ser pago pelos pais para permanência das crianças nessas instituições de ensino. Ela cita:

(...) se a educação é destinada à classe dominante, ela terá o objetivo de preparar pessoas capazes de deleitar-se com a vida e governar. Um exemplo típico desse tipo de escola é o chamado "ginásio rural" ou "escolas novas", que surgiram agora em quase todos os países europeus, onde a aristocracia intelectual e rica educa seus filhos (Krupskaya, 2017, p. 66).

As concepções da Escola Nova foram defendidas, no Brasil, a partir do Manifesto dos Pioneiros da Educação Nova, publicado em 1932, e, cuja da construção participaram nomes conhecidos da educação brasileira, como Anísio Teixeira, Fernando de Azevedo e Cecília Meirelles.

Saviani (2011) relata as diversas tendências educativas que se colocaram ao longo da história da educação brasileira como alternativas ao projeto hegemônico de cada época. Na década de 1960, partir de uma confluência das necessidades de alfabetização colocada pelos coronéis da época, e da necessidade de reconstrução da pedagogia católica, o autor indica o surgimento do Movimento de Educação de Base (MEB), ligado à igreja Católica, e o Movimento de Educação de Adultos com Paulo Freire, como um dos preceptores. Este atua a partir das necessidades de manutenção da ordem social estabelecida para a construção de uma proposta pedagógica que favorecia a reflexão e problematização sobre as relações sociais estabelecidas no cotidiano dos educandos. Freire também 
se torna referência ao fundar uma nova corrente educativa, a educação libertadora, baseada nesses princípios. Realizou no nordeste brasileiro, programas de alfabetização de jovens e adultos como o "De pé no chão também se aprende a ler" e a alfabetização de adultos em 40 dias interrompidos com a ditadura militar no Brasil, e a perseguição política que ele viria a sofrer.

Entre 1962 e 1969 funcionaram no Brasil os ginásios vocacionais, também buscando romper com a educação tradicional e implementar aspectos mais relacionados com as questões sociais aos seus projetos pedagógicos. Nakamura (2016) ressalta como inovações desses espaços, como a implementação de novas matérias no currículo e sua adequação à realidade local, as condições de trabalho do professor com dedicação exclusiva e tempo de planejamento, o limite de 30 alunos por turma, o estreitamento de relações com a comunidade a partir de metodologia de ensino chamada "estudos do meio", os projetos de ação comunitária, a criação de Associações de Pais e Amigos dos Ginásios Vocacionais, etc. Cupertino (1990) enfatiza a preocupação desses ginásios com a transformação social ao realizar estudo de comparação de um Ginásio Vocacional com uma Escola de Aplicação, outra proposta de inovação educacional da época. Para ela,

o G.V., por sua vez, desde a escolha do 'core curriculum', já deixava clara a sua prioridade: a de capacitar seus alunos a agir, não enquanto indivíduos, mas como parte do grupo, segundo padrões coletivos, com objetivo de modificar 'o social' (Cupertino, 1990)

Assim como outros movimentos de renovação educacional, os ginásios experimentais foram reprimidos e fechados durante a ditadura militar no Brasil, como cita o Estudo de Cupertino (1990). Nesse período não havia muito espaço para a execução de práticas pedagógicas escolares que reafirmassem outro modelo de sociedade, mesmo que essas ideias 
continuassem a vigorar entre os que se contrapunham à ditadura.

No entanto, enquanto a educação contra-hegemônica ganhava espaço nos meios de comunicação, com a criação de vários jornais da esquerda. Com a promulgação do Ato Institucional n.5 (Al $5^{1}$ ) vários desses jornais passaram a funcionar clandestinamente. Mesmo com o fim da censura, muitos desses jornais continuavam sofrendo o boicote dos instrumentos oficiais ou de atos de vandalismo, dificultando sua continuidade, como exemplificado no site Memórias da Ditadura (http://memoriasdaditadura.org.br/imprensa-alternativa/): "com o fim da censura, cresceu a fiscalização da receita federal. Depois, veio o terrorismo de direita, com invasão de sucursais e, para piorar, bombas nas bancas que vendiam jornais alternativos".

Com o enfraquecimento da ditadura militar e num momento em que o projeto oficial de sociedade e de pais estava em conflito, claro, com vários setores da sociedade, alguns projetos educacionais ganham espaço e sua existência se faz possível. Nascem, então, propostas como escolas de educação básica ou infantil. Almeida (2014. p. 74) registra que nessa época são criadas a Escola Vila, em Fortaleza/Ceará (CE) e com fundação em 1981; a Associação pró-educação Vivendo e Aprendendo, em Brasília/Distrito Federal (DF), com criada no ano de 1982; o Colégio Viver, em Cotia/São Paulo (SP), com início por volta de 1975; o Instituto Pandavas, em Monteiro Lobato/SP, inaugurada em 1986; O Centro de Estudos Casa Redonda, em Carapicuíba/SP, e estabelecida em 1988.

Além da própria discordância em relação aos objetivos e sociedade

1 O Al5 vigorou entre o final de 1968 até 1978 e autorizava o presidente da República, em caráter excepcional e, portanto, sem apreciação judicial, a: decretar o recesso do Congresso Nacional; intervir nos estados e municípios; cassar mandatos parlamentares; suspender, por dez anos, os direitos políticos de qualquer cidadão; decretar o confisco de bens considerados ilícitos; e suspender a garantia do habeas-corpus (Fonte: Celina Maria de Araujo. Recuperado a partir de http://cpdoc.fgv.br/producao/dossies/Fatos/magens/Al5) 
perpetuada pela escola moderna baseada no capitalismo, também o novo ciclo tecnológico que vivenciamos hoje contribui para questionar o formato da escola tradicional. Uma nova sociedade e, por que não dizer, um capitalismo que se reorganiza e se transforma continuamente exige também, constantemente, a criação de novos modelos de homem capitalista. Nesse sentido, falar em crise da escola tradicional e a busca por novos formatos educacionais se tornou lugar comum nas sociedades, tanto para aqueles que buscam superar esse sistema econômico mundial, quanto para aqueles que desejam evitar as constantes crises capitalistas.

\section{A Construção de Redes}

Nos últimos anos, no Brasil e no mundo, o número de escolas e propostas educativas alternativas vem aumentando em número e encontrando apoio na disseminação de informações sobre elas. Vários grupos e pessoas têm se dedicado a conhecer e divulgar propostas educacionais que fogem ao padrão da escola tradicional. A crescente relação entre o campo da educação com a comunicação tem sido frutífera para as escolas alternativas, culminando em vários espaços de discussão e construção coletiva, além de mapeamentos de práticas pedagógicas, difundindo as experiências, a criação de redes e articulações entre educadores e interessados pelo tema com posterior difusão de eventos e livros.

Um desses espaços foi a criação da rede Românticos Conspiradores (RC), por educadores que iniciaram um processo de discussão a partir da construção de uma rede colaborativa virtual. Ela se forma em 2009 e hoje conta com cerca de 2490 membros inscritos. Essa rede foi criada com a intenção de reunir pessoas que militam pela transformação da educação pública, através da promoção da "comunicação e o apoio mútuo entre pessoas, organizações e projetos que tenham por objetivo contribuir para a 
superação dos arcaicos paradigmas educacionais vigentes" (Românticos Conspiradores [RC], 2008). A Rede dos RC se organiza a partir de uma carta de princípios formulada ainda em 2008, cujos pontos referem-se ao educarse na integralidade, na solidariedade, na diversidade, na realidade, na democracia e com dignidade (RC, 2008). Também a partir da organização dos RC, foi construído o documento "Mudar a Escola, Melhorar a Educação: Transformar um País", que tem a intenção de ser o terceiro de dois famosos manifestos educacionais difundidos no Brasil, um em 1932, dos Pioneiros da Educação, e outro em 1959, que esteve na origem das Escolas Experimentais e dos Ginásios Vocacionais. Construído ao longo de dois anos e entregue oficialmente ao Ministério da Educação em 2013, o documento traz 19 indicadores para a educação nacional, defendendo, por exemplo, a participação da comunidade na gestão das escolas por meio de decisões colegiadas, a diversificação das aprendizagens a partir da implementação de comunidades de aprendizagem, a defesa da educação integral e de tempo integral; abolição da competição e premiação nos sistemas de educacionais; a não separação entre desenvolvimento afetivo e emocional do desenvolvimento cognitivo; a garantia de matrícula em todos os níveis; a defesa da educação domiciliar; a defesa de uma avaliação formativa, contínua e sistemática etc (Românticos Conspiradores [RC], 2008).

Outro modelo que se difundiu com o objetivo de detectar e expor propostas educacionais foram inúmeros mapeamentos de projetos alternativos. Basicamente refere-se à iniciativas individuais ou de pequenos grupos de pessoas que transitaram pelo Brasil e pelo mundo conversando e conhecendo práticas educativas inovadoras e, ao fim, difundiram suas experiências em livros, eventos ou sites, realizando a comunicação entre as cidades/projetos visitados. 
Nessa perspectiva estão os mapeamentos realizados pelo projeto Caindo no Brasil e pelo Edu On Tour. O primeiro tem por objetivo "conhecer as diversas realidades nacionais e iniciativas educacionais que estão realmente fazendo a diferença na sociedade". Em 2014, tornou-se um "negócio social" que com o objetivo de "empoderar projetos e pessoas e promover troca de ideias, o compartilhamento de conhecimentos e a formação de redes" (Caindo no Brasil, http://mapa.caindonobrasil.com.br/). O mapeamento desenvolvido pelo Caindo no Brasil tem como foco a inter-relação entre conhecimentos acadêmicos e das comunidades e o impacto social produzido pela educação promovida na instituição visitada.

Já o Edu On Tour é uma proposta do Presente!, um grupo internacional que tem por objetivo o desenvolvimento da educação alternativa. O projeto durou quatro meses, no ano de 2013, visitando cidades brasileiras e teve como finalidades principais "descobrir e aprender", "unir e conectar" e "promover e mostrar".

O projeto REEVO (http://map.reevo.org/) também traz a proposta de mapeamento internacional de práticas alternativas em educação, mas em um formato diferenciado: cada prática educativa inscreve seu projeto no mapa, respondendo a um questionário, onde são solicitadas algumas características. $\bigcirc$ mapa $^{2}$ ainda organiza as 735 práticas educativas inscritas por tipo de experiência, por método pedagógico, por gestão e por enfoque alternativo. Nesta última categoria, as práticas são divididas em "educação progressista", "educação livre/libertária", "educação democrática", "educação holística", "educação popular", "etnoeducação" e "educação sem escolas".

Além do mapa coletivo e das diversas formas de separação e aglutinação das experiências descritas, o REEVO também dissemina diversos artigos. Os

${ }^{2}$ O Mapa está disponível no endereço http://map.reevo.org/ 
fundadores do grupo também construíram um documentário sobre a escola e a educação atual intitulado "educação proibida".

Essas e outras iniciativas estiveram presentes na I Conferência Nacional para uma Educação Nova (CONANE), realizada em novembro de 2013 em Brasília/DF. A Conferência foi organizada em cooperação entre o projeto Autonomia e pelo coletivo Gaia, reunindo mais de 30 experiências educacionais, além de marcar a entrega do Manifesto organizado pelos Românticos Conspiradores aos representantes do Ministério da Educação.

Em 2015, a segunda CONANE assume caráter internacional e sua organização foi descentralizada, participando dessa edição desde instituições a educadores individuais. Essa conferência ocorreu no Centro Educacional Unificado - CEU - Heliópolis Prof. ${ }^{a}$ Arlete Persoli, onde se desenvolve o projeto Bairro-Escola Heliópolis, a partir da perspectiva da Cidade Educadora. Esse evento teve uma metodologia diversificada, contando com mesas e painéis de discussão, oficinas e rodas de conversa, um "varal de experiências" aberto e atividades culturais. Assim como na anterior, contou com a participação de representantes do Ministério da Educação, que utilizaram o espaço para lançar e divulgar uma chamada pública para o mapeamento de práticas educativas alternativas.

A CONANE volta à Brasília em 2017, realizada em novo formato com a disseminação das experiências educativas a partir de mesas de discussão e filmes, e a construção de Círculos de Partilha, Aprendizagem e Ação para debates de temas específicos que culminaram com a construção de planos de ação com duração de dois anos, até a próxima conferência.

Na esfera governamental, foi criado um Programa de Estímulo à Criatividade na Educação Básica que por meio de uma chamada pública lançada em 2015 identifica e certifica escolas inovadoras de todo o país - fruto dos 
esforços de um Grupo de Trabalho instituído pelo Ministério da Educação através da portaria MEC 751/2015, sob a presidência de Helena Singer, responsável pela orientação e acompanhamento da iniciativa para inovação e criatividade na educação básica no ministério. Esse GT é formado por diversas secretarias do MEC e representações de instituições e projetos de educação alternativa em atuação no Brasil, hoje. Outra ação do GT foi a criação de grupos descentralizados, por estado, que agregam novas pessoas ao trabalho. Essas iniciativas, desde a nomeação de Helena Singer até a formação dos GTs, foram recebidas, com esperança, entre os militantes da área e educadores que buscam por novas possibilidades educacionais. Uma das principais contribuições do grupo para a educação alternativa foi a criação de critérios definidores e indicadores que permitem, objetivamente, classificar as escolas em inovadoras ou não. Esses critérios foram organizados em cinco eixos ${ }^{3}$ :

Gestão - corresponsabilização na construção e gestão do projeto político pedagógico;

Currículo - desenvolvimento integral, produção de conhecimento e cultura e sustentabilidade social, econômica, ecológica e cultural;

Ambiente - espaço compatível com novas práticas educativas, ambiente acolhedor e solidário;

Metodologia - protagonismo do estudante, personalização, organização de projetos;

Intersetorialidade - construção de estratégias intersetoriais e em rede, envolvendo a comunidade, para a garantia dos direitos fundamentais dos estudantes.

No entanto, com o golpe institucional sofrido no país em 2016 e a mudança de governo, a proposta morre por inanição, sem o apoio institucional e a suspensão dos poucos recursos destinados à área da educação inovadora e criativa.

${ }_{3}^{3}$ Cada eixo é mais bem explicado no site http://criatividade.mec.gov.br/o-que-e-inovacao-e-criatividade. 


\section{Qual o Significado da Construção das Redes de Escolas e Educadores?}

mundo globalizado, as tecnologias de informação, as possibilidades de percorrer grandes espaços em pouco tempo, tanto fisicamente quanto virtualmente geram novas maneiras de ser e propagar ideias inovadoras em educação.

Diante da realidade exposta, nos cabe a pergunta: quais as consequências dessas redes, da disseminação das metodologias escolares e das ações propostas por elas para a educação alternativa no Brasil?

Até bem pouco tempo, as práticas pedagógicas alternativas eram profundamente enraizadas nas necessidades dos espaços em que eram construídas, onde tanto os problemas quanto as soluções encontradas tinham como ponto de partida a própria experiência pedagógica, um grupo de pessoas que viviam cotidianamente essa experiência ou, no máximo, tinham como referência práticas pedagógicas mundialmente famosas, mesmo que distantes no tempo e no espaço, como a Escola da Ponte ou a experiência de Summerhill.

Com as crescentes facilidades de disseminação e alteração dos fluxos informacionais se ampliam as possibilidades de contato com novas propostas educacionais, torna-se possível conhecer novas formas de educação, novos objetivos educacionais, novas metodologias, novos termos, novas pessoas e novos problemas enfrentados. O grande fluxo de informações desorganizadas sobre educação alternativa se torna caótico. A internet e os projetos de mapeamentos permitem encontrar escolas e espaços educativos em poucos minutos, mas a partir de critérios distintos e nem sempre comuns, assim como permite a qualquer pessoa inserir nesses bancos de dados a proposta em que atua, classificando-as como alternativa e elencando suas 
características principais.

Lemos e Cunha, reconhecem as dificuldades impostas à organização do pensamento impostas pela alta velocidade de circulação de informação, mas indicam que o grande fluxo de informações também é benéfico à construção do conhecimento indicando que "[...] o tempo real pode inibir a reflexão do discurso bem construído e a argumentação. Por outro lado, o clique generalizado permite a potência da ação imediata, o conhecimento simultâneo e complexo, a participação ativa dos diversos fóruns sociais" (Lemos e Cunha apud Almeida, 2014, p. 65). Illich (2002), ao contrário, tece esse diálogo entre a relação entre o homem, informação e a tecnologia apontando para o resultado desastroso. Para o autor,

[...] em cada computador há uma opressão com a promessa de abrir novas estradas para os dados, para as substituições, para as inversões e a impressão instantânea. Um novo tipo de texto modela a mentalidade de meus alunos: o texto que sai da impressora não tem âncora, não pode pretender ser uma metáfora nem um original da mão do autor. Como sinais de um navio fantasma, suas fibras digitais formam moldes de imprensa arbitrários na tela, fantasmas que aparecem para desvanecer-se depois. Cada vez menos gente se aproxima do livro como um porto de significado. Sem dúvida, ainda transmite à alguns a admiração e alegria, perplexidade ou amargo pesar; mas temo que, para a maioria, sua legitimidade consiste em ser pouco mais que uma metáfora apontando para a informação. (Illich, 2002, p.156)

Sibilia confirma as ideias de lllich, quando afirma que a grande quantidade de informações e trocas que realizamos, ao invés de produzir pensamento, nos anestesia da realidade, causando a dispersão e produzindo o efeito contrário: a não-comunicação. "A sociedade informacional não conecta, mas tende a desligar, dificultando as possibilidades de dialogar ou de compor uma experiência junto com os demais" (Sibilia, 2016, p. 186).

No entanto essa autora leva para a atuação do indivíduo a responsabilidade de reflexão sobre o fluxo de informações recebidas. Ao expor a maneira como se formam as subjetividades humanas tanto na escola moderna 
quanto nessa nossa era da informática, onde tempos e distâncias se tornaram fluidos, indica que

(...) a simples disponibilidade de alternativas interativas ou a possibilidade de intervir no desenvolvimento das narrativas como um "usuário ativo", por exemplo, não garantem a qualidade dos resultados nem na sua transformação em diálogo, experiência ou pensamento: isso dependerá das operações que cada um realize. (Sibilia, 2016, p.186).

Assim, no que diz respeito à construção da subjetividade, a autora indica que a disponibilidade de informação ou a possibilidade de trocas mútuas não é, por si só, efetiva para a construção do pensamento.

Reconhecendo que diferenças entre a construção do pensamento em cada indivíduo e enquanto grupo social existem, mas também semelhanças podem ser encontradas, tendemos a analisar os fluxos de informações sobre práticas pedagógicas alternativas e a construção de redes de informação, sob uma ótica semelhante à que Sibilia analisa a construção do pensamento individual. Assim como, para Sibilia, o fluxo de informações a que cada indivíduo tem acesso pode gerar a desinformação e o pensamento caótico, tendemos a pensar que a simples disseminação das práticas educativas não gera, necessariamente, um processo de reflexão em cada uma delas. Ao contrário disso, pode gerar efeito oposto: um fluxo tamanho de informação sem consistência e adensamento que impeça o processo de análise concreta de cada prática educativa.

Diante desse cenário, o aprendizado numa sociedade conectada exige novas habilidades dos indivíduos e, acrescentamos, nos grupos

agora não basta registrar e armazenar, pois costumam faltar o tempo e a capacidade para filtrar ou metabolizar as informações que fluem constantemente e se acumulam às toneladas. A subjetividade midiática não se sente ameaçada pela alienação do desconhecimento, mas pela sensação de vazio e pela desorientação: por certa perda de sentido derivada da falta de consistência daquilo que se lê ou se escreve nas redes, por exemplo (Sibilia, 2016, p. 197). 
Ao contrário da tentativa de evitar ou reverter o grande fluxo de informações, a autora defende como estratégia para a construção do pensamento o adensamento dessas informações. Criar mecanismos subjetivos de ancorar essas informações, compreendendo-as de maneira conjunta com outras, aglutinando-as para poder compreendê-las melhor e transformá-las em experiência e pensamento seria a tarefa dos que vivem nesse mundo hiperconectado. Para Sibilia, a criação dessas redes são a tentativa de compreender um mundo supersaturado de informações a partir do adensamento dessas e da possibilidade de refreá-las e trazê-las à consciência. Ela descreve que

(...) hoje a estimulação abundante mas escasseia a capacidade de incorporar esses estímulos, que deslizam sem se assentarem na subjetividade por meio da consciência. Esse seria um dos motivos, aliás, pelos quais se revela tão importante tecer redes, já que estas multiplicam as conexões e permitem habitar de modo conjunto a torrente informacional, produzindo uma densidade capaz de desacelerar essa avalanche e captar de algum modo o que se sucede tão rapidamente, transformando-o em experiência (Sibilia, 2016, p. 91).

Em se tratando da forma como as redes de educadores/ escolas/ experiências educativas alternativas são utilizadas para o adensamento e reflexão sobre educação, e não só como um fluxo irrestrito e caótico de informações sobre experiências pedagógicas, já é possível perceber uma alteração na caracterização, a partir da programação da primeira e da última Conane. Na primeira conferência, a necessidade de reconhecimento das experiências fez jorrar dezenas de experiências educativas, num formato onde o fluxo de informações ainda era de emissor/ palestrante e receptor/ público do fluxo informacional. Num momento posterior, na última edição da Conane, os espaços de emissão de informação sobre as práticas educativas foram substituídos por filmes sobre as instituições, discutidos conjuntamente com pesquisas acadêmicas na área e possibilitando um debate mais aprofundado sobre as práticas, para além da simples informação sobre elas. 
Também se buscou o adensamento dessas informações a partir da sugestão de criação de um espaço virtual que reunisse as informações sobre práticas educativas inspiradoras.

Essa forma de adensamento dos fluxos informacionais sobre as práticas alternativas impede que as trocas de informações construídas nesses eventos se restrinjam a discursos vazios de exaltação, de determinadas práticas pedagógicas, sem uma reflexão aprofundada sobre elas ou a busca de se deter mais profundamente para analisá-las.

Se, antes da popularização dos meios de comunicação e informação para disseminação de práticas educativas, a reflexão sobre o real, a análise das metodologias, dos problemas e a busca de soluções se dava no dia a dia e no local da ação, a partir de tentativas reais, hoje as redes possibilitam aprender com o erro dos outros, de experiências educativas distantes. 0 processo de construção das práticas educativas não é mais uma característica exclusiva de cada instituição, mas o fluxo de informações tende a possibilitar que os caminhos e dificuldades encontradas possam ter soluções discutidas nos coletivos externos às práticas, por mais que se reconheça que as condições de cada instituição são únicas.

Nesse sentido, mais uma vez ressalta-se a necessidade das redes de produzir momentos que extrapolam a simples apresentação e exaltação de práticas que "deram certo", mas que avancem na análise dos percursos percorridos, dos problemas enfrentados, dos objetivos de cada prática e das diferenças entre elas, disseminando informações, e possibilitando os espaços para pensar sobre elas.

Outra característica marcante das redes de educadores alternativos, observada tanto nos Românticos Conspiradores quando nas Conanes, é a atuação política e o caráter propositivo desses grupos. Assim, ao mesmo 
tempo em que realizam uma análise da realidade e elencam demandas pela qual lutar, também oferecem caminhos de ação bem definidos como, por exemplo, os pontos elencados no Manifesto dos Românticos Conspiradores, enquanto pauta de luta, e a chamada pública do Ministério da Educação, enquanto ação que visibiliza a educação alternativa ao mesmo tempo em que delimita critérios para que as propostas educativas sejam consideradas como inovadoras. Assim, a ação política também tem funcionado como um organizador da reflexão sobre a educação que se deseja. Cabe ressaltar que, essas iniciativas para as formulações políticas são interpretações e sistematizações das discussões mais amplas, podendo não as contemplar em sua totalidade.

\section{Considerações finais}

Tentou-se traçar alguns comentários e análises sobre os processos de construção de redes de educação alternativa no Brasil, indicando sua função para as práticas locais e para uma construção efetivamente global da educação alternativa. Assim como alguns cuidados para que as redes não se percam no amontoado de fluxos de informação existentes atualmente.

Recusa-se a ideia de que as redes de educação alternativa, eventos e grupos de discussão são simples informações sem significado, simples espaços de divulgação, mas, ao contrário disso, são espaços coletivos de construção de propostas educativas e de reflexão sobre o formato que estas devem assumir. $\bigcirc$ fluxo de informações sobre práticas educacionais alternativas presentes nas redes tanto presenciais quanto virtuais tem possibilitado um adensamento de informações na tentativa de uma reflexão sobre a prática e não apenas a disseminação de informações, o que se 
traduziu inclusive nas diferenças de programação da Conane ao longo do tempo e de sua capitalização. Esse adensamento do fluxo de informações e o processo de reflexão coletiva a partir delas também permitiu uma atuação política e a definição de pautas comuns às redes de práticas pedagógicas. Nesse sentido, as Conanes, encontros dos Românticos Conspiradores, outros seminários e eventos da área ou a formulação coletiva de documentos ou outros textos não podem ser vistos como simples eventos, mas como espaços de construção de subjetividades pedagógicas e, nesse caso, é imprescindível que os participantes estejam abertos a essas possibilidades de reflexão e auto reconstrução e não somente de exposição elogiosa do próprio trabalho. Assim, chama-se atenção para a maior importância da reflexão que propriamente da fala nesses espaços. Bem como a elaboração de espaços que possibilitem o conhecimento dos processos de construção, com todos os entraves e soluções encontradas, e não apenas dos produtos finais construídos.

Data da submissão: $31 / 07 / 2019$

Data do aceite: $23 / 01 / 2020$ 


\section{REFERÊNCIAS}

Almeida, Gabriela Freitas de. (2014). Para onde caminham as escolas?. (Dissertação de Mestrado). Universidade de Brasília, Programa de PósGraduação em Educação, Brasília. Recuperado a partir de http://repositorio.unb.br/handle/10482/16395.

Almeida, Vanessa Sievers. (2015). Educação e tradição: reflexões a partir de Hannah Arendt e Walter Benjamin. Revista Entreideias, Salvador, 4(2), 106119. Recuperado a partir de https://portalseer.ufba.br/index.php/entreideias/article/viewFile/9761/1025 0 .

Cambi, Franco. (1999). História da Pedagogia. Álvaro Lorencini (Trad.). São Paulo: Fundação Editora da UNESP.

Cupertino, Maria Amélia Marcondes. (1990). Dilemas da Escola Renovada. (Dissertação de Mestrado). Universidade Estadual de Campinas, Programa de Pós-Graduação em Educação, Campinas. Recuperado a partir de http://repositorio.unicamp.br/browse?type=author \&value=Cupertino\%2C+ Maria+Amelia+Marcondes\&value_lang=pt_BR.

Illich, I.(2007). Sociedade Desescolarizada. Porto Alegre: Editora Deriva.

Illicg, I. (2002). En el viñedo del texto. Etologia de la lectura: um comentário del "didascaliscon" de Hugo de Sem Victor. México: FCE

Krupskaya, N. K. (2017). A construção da pedagogia socialista: escritos selecionados. São Paulo: Expressão Popular.

Nakamura, M. E. F. P. (2016). Os Ginásios Vocacionais Estaduais: algumas considerações iniciais acerca desta proposta educacional da década de 1960. In: História oral, práticas educacionais e interdisciplinaridade, Anais 13 Encontro Nacional de História Oral, Porto Alegre: Universidade Federal do Rio Grande do Sul. Recuperado a partir de http://www.encontro2016.historiaoral.org.br/resources/anais/13/146186987 O_ARQUIVO_TRABALHOSUBMETIDO_XIIIENCONTRONACIONALDEHISTORIAOR AL_2016.pdf. Acesso em 26/10/2017.

Passos, L. F., Ferreira, V. L. \& Matte, C. H. (2013). Escola Experimental da Lapa: a cultura material revelando uma experiência curricular renovadora. In: Circuitos e Fronteiras da História da Educação no Brasil, 7 Congresso Brasileiro de História da Educação, Cuiabá: Universidade Federal de Mato Grosso. Recuperado de http://sbhe.org.br/novo/congressos/cbhe7/pdf/10\%20PATRIMONIOEDUCATIVO\%20E\%20CULTURA\%20MATERIAL\%20ESCOLAR/E SCOLA\%20EXPERIMENTAL\%20DA\%20LAPA.pdf 
Românticos Conspiradores (RC). (2008). Apresentação. São Paulo,

Recuperado a partir de http://romanticosconspiradores.ning.com/page/sobre-o-rc.

Saviani, D. (2008). Teorias pedagógicas contra hegemônicas no Brasil.

Revista do Centro de Educação e Letras da Unioeste, Foz do Iguaçu, 10(2), 11-28. Recuperado a partir de http://e-

revista.unioeste.br/index.php/ideacao/article/view/4465/3387. Acesso em $08 / 01 / 2018$

Saviani, D. (2011) História das ideias pedagógicas no Brasil. Campinas, SP:

Autores Associados.

Sibilia, Paula. (2012). Redes ou paredes: a escola em tempos de dispersão.

Vera Ribeiro (Trad.). Rio de Janeiro: Contraponto. 


\section{Biografia}

E-mail: prof.gabialmeida@gmail.com / ORCID: https://orcid.org/0000-00033594-9841 